\title{
Genome-Scale Metabolic Model of the Human Pathogen Candida albicans: A Promising Platform for Drug Target Prediction
}

\author{
Romeu Viana ${ }^{1,2}$, Oscar Dias ${ }^{3}{ }^{10}$, Davide Lagoa ${ }^{3}$, Mónica Galocha ${ }^{1,2}$, Isabel Rocha ${ }^{3,4, *}$ and \\ Miguel Cacho Teixeira ${ }^{1,2, *(1)}$ \\ 1 Department of Bioengineering, Instituto Superior Técnico, Universidade de Lisboa, 1049-001 Lisbon, Portugal; \\ romeuviana@tecnico.ulisboa.pt (R.V.); monicagalocha@gmail.com (M.G.) \\ 2 Institute for Bioengineering and Biosciences, Biological Sciences Research Group, Instituto Superior Técnico, \\ 1049-001 Lisbon, Portugal \\ 3 Centre of Biological Engineering, Universidade do Minho, 4710-057 Braga, Portugal; \\ odias@ceb.uminho.pt (O.D.); dlagoa@ceb.uminho.pt (D.L.) \\ 4 Instituto de Tecnologia Química e Biológica António Xavier, Universidade Nova de Lisboa (ITQB-NOVA), \\ 2780-157 Oeiras, Portugal \\ * Correspondence: irocha@itqb.unl.pt (I.R.); mnpct@tecnico.ulisboa.pt (M.C.T.)
}

Received: 27 July 2020; Accepted: 8 September 2020; Published: 11 September 2020

\begin{abstract}
Candida albicans is one of the most impactful fungal pathogens and the most common cause of invasive candidiasis, which is associated with very high mortality rates. With the rise in the frequency of multidrug-resistant clinical isolates, the identification of new drug targets and new drugs is crucial in overcoming the increase in therapeutic failure. In this study, the first validated genome-scale metabolic model for Candida albicans, iRV781, is presented. The model consists of 1221 reactions, 926 metabolites, 781 genes, and four compartments. This model was reconstructed using the open-source software tool merlin 4.0.2. It is provided in the well-established systems biology markup language (SBML) format, thus, being usable in most metabolic engineering platforms, such as OptFlux or COBRA. The model was validated, proving accurate when predicting the capability of utilizing different carbon and nitrogen sources when compared to experimental data. Finally, this genome-scale metabolic reconstruction was tested as a platform for the identification of drug targets, through the comparison between known drug targets and the prediction of gene essentiality in conditions mimicking the human host. Altogether, this model provides a promising platform for global elucidation of the metabolic potential of $C$. albicans, possibly guiding the identification of new drug targets to tackle human candidiasis.
\end{abstract}

Keywords: Candida albicans; global stoichiometric model; drug targets; metabolic reconstruction; gene essentiality

\section{Introduction}

In the last few decades, a significant increase in nosocomial fungal infections has been observed, and Candida species are by far the most common cause of invasive fungemia in humans $[1,2]$. Among Candida species, Candida albicans is the main etiological agent of invasive candidiasis [3,4], being associated to high mortality rates [4]. Together with its virulence traits [5,6], its ability to acquire drug resistance [7-9] makes this opportunistic pathogen a severe threat.

Only three classes of antifungal drugs are licensed to treat Candida infections (azoles, echinocandins, and amphotericin B), and only some azoles and echinocandins are recommended as first-line agents [10]. Currently, there has been a rise in the frequency of multidrug-resistant clinical isolates, and therapeutic 
options are running low. This is true for C. albicans, but even more so for other emerging non-albicans Candida species, such as C. glabrata, C. krusei and C. auris. For example, in recent studies, almost $40 \%$ of the Candida glabrata isolates shown to be resistant to at least one echinocandin were also resistant to fluconazole [11,12]. In non-albicans pathogenic Candida species, the scenario is even more frightening, as several of them display, either intrinsic or easily acquired resistance to several of the available antifungal agents. For example, in a recent case, Candida auris isolates were identified as resistant to the three classes of available antifungal drugs, further raising public concern on the future efficacy of current antifungal therapeutic options [13]. The identification of new drug targets and new drugs is crucial to overcome the increase in therapeutic failure.

Genome-scale metabolic models have the potential to provide a holistic view of cell metabolism. Historically, these global mathematical descriptions of cell metabolism have mostly been linked to metabolic engineering of microbial cell factories, given their potential to simulate global metabolic behavior and provide hints to guide experimental optimization of such organisms for the production of added-value compounds [14]. However, recent examples have shown the potential of these models in the quest for novel drug targets in pathogenic organisms [15-19]. For example, Abdel-Haleem et al. in 2018, described the reconstruction of genome-scale metabolic models for five life cycle stages of Plasmodium falciparum, enabling the identification of potential drug targets that could be used as both, anti-malarial drugs and transmission-blocking agents [20].

Here, we present the first validated in silico genome-scale metabolic reconstruction of $C$. albicans, the iRV781. This model is provided in the well-established SBML format and can easily be read in most metabolic engineering platforms such as OptFlux [21] and COBRA [22]. The model validation procedure is detailed, and evaluation of the potential of this model for research is advanced for new drug targets in this fungal pathogen.

\section{Materials and Methods}

\subsection{Model Development}

The Candida albicans iRV781 genome-scale metabolic model was developed following the methodology represented in Figure 1, using merlin 4.0.2 [23] for the reconstruction process, as described elsewhere [24], and OptFlux 3.0 [21], for the curation and validation of the model. All predictions were performed using the IBM CPLEX solver (IBM, Armonk, NY, USA). Merlin is a platform that enables the semi-automatic reconstruction of metabolic models, providing a user-friendly interface that assists the user in the manual curation process [19].

\subsection{Genome Annotation and Assembling the Metabolic Network}

The genome sequence of the reference strain Candida albicans SC5314 was obtained from NCBI's Assembly database, accession number ASM18296v3 (www.ncbi.nlm.nih.gov/assembly) [25] and the Taxonomy ID from NCBI (www.ncbi.nlm.nih.gov/taxonomy) [26], which is required by merlin to univocally identify the organism under study throughout the reconstruction process. In order to establish a proximity between species, the $16 \mathrm{~S}$ rRNA gene of several known closely related species was used to construct a Phylogenetic tree, the sequences being retrieved from NCBI's database and aligned using MEGA X 10.0.5 (Pennsylvania State University, State College, PA, USA) [27]. The evolutionary history was inferred by using the Maximum Likelihood method and Tamura-Nei model [28] (Figure S1). The genome-wide functional annotation was processed by merlin based on taxonomy and frequency of similar sequences trough remote Basic Local Alignment Search Tool (BLAST) [29] similarity searches to the UniProtKB/Swiss-Prot database [30] (http://www.UniProt.org/) and HMMER [31]. Protein-reaction associations, available in the Kyoto Encyclopedia for Genes and Genomes (KEGG) BRITE database, were used to assemble the draft network. All reactions classified as spontaneous or non-enzymatic were also included in the first draft of the model. The assembly of the metabolic network is performed 
by merlin, using genome annotation to determine which reactions will be included in the model, based on an algorithm described in detail elsewhere [23].

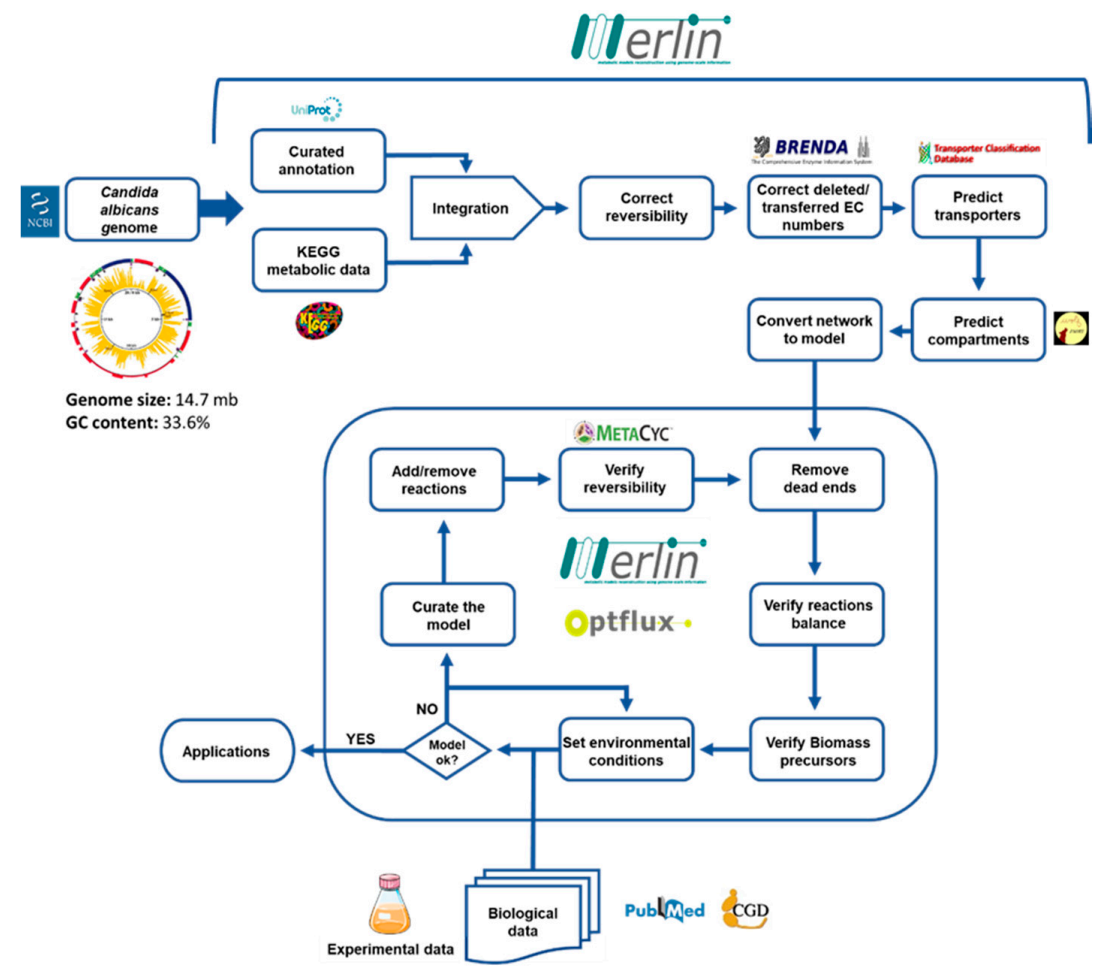

Figure 1. Methodology for the reconstruction of the Candida albicans iRV781 metabolic model. Adapted from [14].

\subsection{Reversibility and Balancing}

In order to ensure that all reactions in the network are balanced, unbalanced reactions were identified, using the corresponding merlin tool, manually verified and corrected. Reaction reversibility was also confirmed to avoid gaps and mispredictions of the model, through the corresponding merlin tool and using Braunschweig Enzyme Database (BRENDA) [32] as reference and the data provided elsewhere [33]. Since there are no guarantees that the EC numbers available in the different databases will be updated, a manual inspection was also performed to correct a few cases of enzymes with deleted/transferred EC numbers, using public databases (BRENDA [34], UniProt, MetaCyc [35] and KEGG [36]) and literature search.

\subsection{Compartmentalization}

This model includes four compartments: Extracellular, cytoplasm, mitochondrion and cytoplasmic membrane. The prediction of compartments for each enzyme and carrier was performed using the WoLF PSORT protein subcellular localization predictor [37].

\subsection{Transport Reactions}

Given the existence of compartments in the model, it is necessary to create transport reactions for the metabolites. Transport reactions were generated using genomic information together with the public database TCDB [35] by merlin's TranSyT [36]. Transport reactions across internal and external membranes for currency metabolites, such as $\mathrm{H}_{2} \mathrm{O}, \mathrm{CO}_{2}$, and $\mathrm{NH}_{3}$, which are often carried by facilitated diffusion, were added to the model with no gene association. 


\subsection{Biomass Equation}

The biomass formation was represented by an equation that includes proteins, DNA, RNA, lipids, carbohydrates, and cofactors, and detailed information for the composition of each one of these macromolecules. The content of each component was determined based on the literature or using experimental data. All the calculations were performed as described previously [38]

For the phosphorus to oxygen ratio the same theoretical ratio used in the S. cerevisiae iMM904 metabolic model was applied, 1.5.This ratio represents the relationship between ATP synthesis and oxygen consumption, indicating the number of orthophosphate molecules used for ATP synthesis per atom of oxygen consumed during oxidative phosphorylation [14]. Three generic reactions contributing to this ratio were automatically generated by merlin, and were updated to replicate the same ratio as in the iMM904 model:

Reaction R00081_C4:

$$
\begin{gathered}
1.0 \text { Oxygen }_{\text {mito }}+4.0 \text { Ferrocytochrome } \mathrm{c}_{\text {mito }}+6.0 \mathrm{H}^{+}{ }_{\text {mito }} \leftrightarrow 2.0 \mathrm{H}_{2} \mathrm{O}_{\text {mito }}+4.0 \\
\text { Ferricytochrome } \mathrm{c}_{\text {mito }}+6.0 \mathrm{H}^{+}{ }_{\text {cyto }}
\end{gathered}
$$

Reaction T02161_C4:

$$
\begin{gathered}
1.0 \text { Ubiquinol }_{\text {mito }}+2.0 \text { Ferricytochrome } c_{\text {mito }}+1.5 \mathrm{H}^{+}{ }_{\text {mito }} \leftrightarrow 1.0 \text { Ubiquinone }_{\text {mito }}+2.0 \\
\text { Ferrocytochrome } c_{\text {mito }}+1.5 \mathrm{H}^{+} \text {cyto }
\end{gathered}
$$

\section{Reaction T00485_C4:}

$$
\begin{gathered}
\text { 1.0 Orthophosphate } \text { mito }+1.0 \mathrm{ADP}_{\text {mito }}+3.0 \mathrm{H}^{+} \text {cyto } \leftrightarrow 1.0 \mathrm{ATP}_{\text {mito }}+1.0 \mathrm{H}_{2} \mathrm{O}_{\text {mito }} \\
+3.0 \mathrm{H}^{+} \text {mito }
\end{gathered}
$$

The final balance reaction:

$$
\begin{gathered}
\text { 3.0 Orthophosphate } \text { mito }+1.0 \text { Oxygen }_{\text {mito }}+3.0 \mathrm{ADP}_{\text {mito }}+2.0 \text { Ubiquinool }_{\text {mito }} \leftrightarrow 3.0 \text { ATP }_{\text {mito }} \\
+5.0 \mathrm{H}_{2} \mathrm{O}_{\text {mito }}+2.0 \text { Ubiquinone }_{\text {mito }}
\end{gathered}
$$

This model also includes ATP requirements for biomass formation and maintenance (non-growth). The growth ATP requirements, 23.346 mmoles ATP/g Dry Cell Weight (DCW), were introduced directly into the biomass equation; this value was calculated based on ATP requirements for biosynthesis of cell polymers for S. cerevisiae, adjusted for the composition in macromolecules of the biomass equation [39].

Non-growth associated ATP maintenance, the amount of ATP required by the cell even when it is not growing, was represented in the model by an equation that forces ATP consumption via a specific flux. The boundaries of this flux were inferred from Candida tropicalis [40]. See File S1 for more detailed information on the computation of the biomass equation.

\subsection{Curation of the Model}

Throughout the curation process, reactions were edited, manually added to, or removed from the model to correct some gaps in the network, using KEGG pathways, MetaCyc Database, and literature data as standards.

\subsection{Strains and Growth Media}

Candida albicans reference strain SC5314 was batch-cultured at $37{ }^{\circ} \mathrm{C}$, with orbital agitation (250 rpm) in Yeast Nitrogen Base (YNB) medium without amino acids: $5 \mathrm{~g} / \mathrm{L}$ glucose (Merck), $6.8 \mathrm{~g} / \mathrm{L}$ YNB (Difco). Solid media contained, besides the above-indicated ingredients, $20 \mathrm{~g} / \mathrm{L}$ agar (Iberagar). 


\subsection{Carbon and Nitrogen Source Utilization Assessment}

The capability of utilizing different carbon and nitrogen sources for cell growth was assessed by comparing in silico predictions to literature data for $C$. albicans. For the few carbon or nitrogen sources for which the model predictions were not consistent with literature data, wet-lab experiments were conducted. Specifically, the utilization of cellobiose, D-Ribose, and mannitol as carbon source, by the C. albicans reference strain SC5314, was evaluated in solid YNB medium containing either $5 \mathrm{~g} / \mathrm{L}$ glucose as control, or $5 \mathrm{~g} / \mathrm{L}$ of either one of the mentioned carbon sources. C. albicans cell suspensions used to inoculate the agar plates, were mid-exponential cells grown in YNB medium with $5 \mathrm{~g} / \mathrm{L}$ glucose, until culture OD600 $\mathrm{nm}=0.5 \pm 0.05$ was reached and then diluted in sterile water to obtain suspensions with OD600nm $=0.05 \pm 0.005$. These cell suspensions and subsequent dilutions $\left(10^{-1} ; 10^{-2} ; 10^{-3}\right)$ were applied as $4 \mu \mathrm{L}$ spots onto the surface of solid YNB media, with the indicated carbon sources. Growth was assessed after incubation at $37^{\circ} \mathrm{C}$ for $24 \mathrm{~h}$.

\subsection{Network Simulation and Analysis}

All the phenotype simulations were performed with Flux Balance Analysis (FBA) in OptFlux 3.0 [21] using the IBM CPLEX solver (IBM, Armonk, NY, USA). Gene essentiality was also determined by OptFlux 3.0 which provides a tool that allows to determine critical genes automatically by performing individual gene knockouts and simulating growth in a given environmental condition. Environmental conditions that simulated the Roswell Park Memorial Institute (RPMI, Buffalo, NY, USA) medium were used, in order to replicate the human serum conditions.

\section{Results and Discussion}

\subsection{Model Characteristics}

The final version of the iRV781 model includes 781 genes associated with 1221 reactions, among which, 174 are transport reactions, and 196 are external drain reactions (exchange constraints set to mimic the environmental conditions), involving 927 metabolites and four different compartments. Analyzing the distribution of proteins by compartments, 205 are plasma membrane proteins, 521 cytoplasmatic proteins and 139 mitochondrial proteins.

In order to elucidate the characteristics of our model we selected well-characterized genome-scale metabolic models of C. glabrata [41] and S. cerevisiae [42] as a comparison. Table 1 shows the distribution of those reactions by the main pathways in the three models. In general, the number of reactions by pathway is quite similar to C. glabrata, S. cerevisiae or both.

Although our model has common standard identifiers for reactions (KEGG ID), it is not possible to assess how the reactions differ among the three models, since the remaining two models do not possess the same identifiers. However, considering only the proteins associated with an EC number, it is possible to make a comparison across the existing models. More than $80 \%$ of the proteins with an associated EC number in our model are also present at least in one of the other 2 models (S. cerevisiae or C. glabrata). Furthermore, about $65 \%$ of the proteins are shared by the three models while about $20 \%$ are unique in iRV781 (Figure 2). The complete list of unique EC numbers can be found in File S3. 
Table 1. Number of reactions in the main pathways of the C. albicans iRV781 model in comparison to C. glabrata iNX804 model and S. cerevisiae iMM904 model.

\begin{tabular}{cccc}
\hline & C. albicans & C. glabrata & S. cerevisiae \\
\hline & iRV781 & iNX804 & iMM904 \\
\hline Amino acid metabolism & 218 & 223 & 217 \\
NAD biosynthesis & 20 & 20 & 24 \\
Cofactors and vitamins & 122 & 120 & 127 \\
Nucleotide metabolism & 120 & 138 & 135 \\
Alternate carbon & 27 & 31 & 27 \\
metabolism & 26 & 18 & 22 \\
Glycolysis/gluconeogenesis & 24 & 20 & 13 \\
Citrate cycle & 18 & 16 & 13 \\
Pentose phosphate & 31 & 28 & 18 \\
pathway & 10 & 13 & 19 \\
Pyruvate metabolism & 29 & 30 & 49 \\
Oxidative & 87 & 81 & 108 \\
phosphorylation & 13 & 9 & 12 \\
Sterol metabolism & 34 & 44 & 52 \\
Fatty acid metabolism & & & \\
Glycerolipid metabolism & & & \\
Phospholipid & & &
\end{tabular}

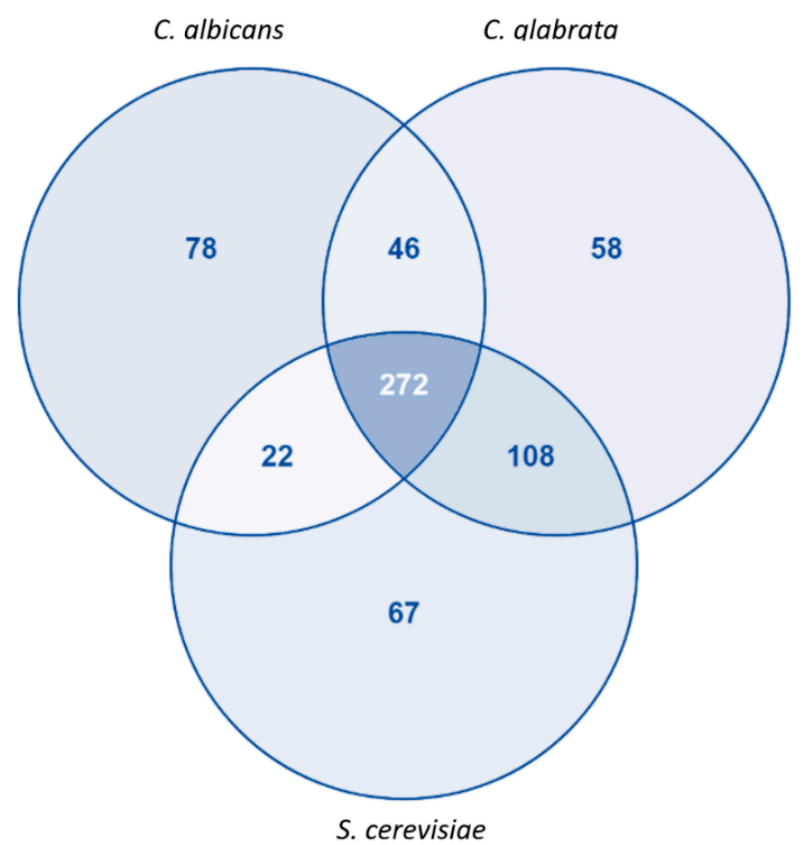

Figure 2. Comparison between C. albicans, S. cerevisiae and C. glabrata proteins with associated EC Numbers present in the genome-scale metabolic models iRV781, iIN800, and iNX804, respectively. Diagram obtained using VENNY2.1 tool [43].

In most cases, the observable differences in EC numbers were related to outdated EC numbers or were compensated with other enzymes that are responsible for the same reactions in the model. However, some cases stand out as potential unique features of $C$. albicans:

- The enzyme 1.13.99.1, inositol oxygenase, responsible for the conversion of myo-inositol into D-glucuronate. This enzyme seems to be involved in resistance to toxic ergosterol analogs [44], 
is also present in other Candida species, including some important pathogens (C. parapsilosis, C. dubliniensis, C. auris), but absent in C. glabrata.

- The enzyme 1.1.1.289, sorbose reductase, responsible for the interconversion of L-sorbose into D-sorbitol. In fact, the presence this enzyme allows C. albicans to use L-sorbose as carbon source [45], unlike S. cerevisiae.

- The enzyme 1.14.19.17, sphingolipid 4-desaturase, responsible for the conversion of dihydroceramide into $\mathrm{N}$-Acylsphingosine. This protein is involved in sphingolipid metabolism, with possible impact in azole resistance in C. albicans [46]. The presence of this enzyme may represent a specific resistance feature of some Candida species, being present in C. parapsilosis, C. dubliniensis, C. auris, but not in C. glabrata.

- The enzyme 1.1.99.2, L-2-hydroxyglutarate dehydrogenase, is a metabolite repair enzyme responsible for the conversion of (S)-2-hydroxyglutarate into 2-oxoglutarate. In other organisms such as plants [47] or humans [48], the inactivation of this enzyme leads to the accumulation of the toxic (S)-2-hydroxyglutarate.

- The enzyme 2.7.1.59, $\mathrm{N}$-acetylglucosamine kinase, responsible for the conversion of $\mathrm{N}$-acetyl-D-glucosamine into $\mathrm{N}$-acetyl-D-glucosamine 6-phosphate. Many yeast species, including S. cerevisiae have lost their ability to utilize $N$-acetyl-D-glucosamine as carbon source, however, genetically altered yeasts are able to use it, based on expression of C. albicans genes [49]. In fact, this enzyme allows $C$. albicans to utilize this carbon source, a feature that is particularly important for its survival inside the phagosomes [50].

- The enzyme 3.5.1.25, $\mathrm{N}$-acetylglucosamine-6-phosphate deacetylase, responsible for the conversion of $\mathrm{N}$-acetyl-D-glucosamine 6-phosphate into D-glucosamine 6-phosphate. Like 2.7.1.59, this enzyme is also involved in $N$-acetyl-D-glucosamine metabolism.

- The enzyme 1.4.3.3, D-amino-acid oxidase, responsible for the conversion of a D-amino acid into a 2-oxo carboxylate and ammonia, is the first enzyme involved in the catabolism of D-amino acids and may allow the utilization D-amino acids as a source of carbon or nitrogen in some yeasts [51]. It may be an interesting feature to be explored in C. albicans.

\subsubsection{Gap Filling and Model Curation}

During the process of manual curation described in the methods section, a total of 66 reactions were manually added to the initial model obtained from the results of re-annotation to fill gaps. Additionally, evidence from the literature was always considered, or of the well-studied S. cerevisiae. On the other hand, 336 reactions were removed from the initial model, have been removed for being unconnected reactions, general reactions, reactions using metabolites that are not included in the model, or reactions for which it was manually verified that the model does not have the enzyme coding gene. Additionally, the compartment of 79 reactions was changed, and 94 reactions were altered to become balanced. The complete list of alterations can be found in File S2.

\subsubsection{Biomass Equation}

The biomass equation (Table 2) includes the composition of proteins, DNA, RNA, lipids, carbohydrates, and cofactors. For the composition of DNA, the whole genome sequence was used to estimate the amount of each deoxyribonucleotide as described in [52], while mRNA, rRNA, and tRNA were used to estimate the total RNA in the cell as described in [14]. For the amino acid composition, the percentage of each codon usage was calculated from the translated genome sequence [52], using the e-Biomass X tool [53]. 
Table 2. Biomass Composition used in the model iRV781. More detailed information is found in File S1.

\begin{tabular}{|c|c|c|c|}
\hline Metabolite & g/gDCW & Metabolite & $\mathrm{g} / \mathrm{gDCW}$ \\
\hline \multicolumn{2}{|c|}{ Protein components } & \multicolumn{2}{|l|}{ Lipids } \\
\hline L-Valine & 0.02001 & Lanosterol & 0.00166 \\
\hline L-Tyrosine & 0.02153 & Squalene & 0.00088 \\
\hline L-Tryptophan & 0.00671 & Ergosterol & 0.00247 \\
\hline L-Threonine & 0.02311 & Phosphatidylserine & 0.00299 \\
\hline L-Serine & 0.02908 & Phosphatidylinositol & 0.00417 \\
\hline L-Proline & 0.01616 & Phosphatidylcholine & 0.00681 \\
\hline L-Phenylalanine & 0.02407 & Phosphatidylethanolamine & 0.00542 \\
\hline L-Methionine & 0.00869 & Cardiolipin & 0.00201 \\
\hline L-Lysine & 0.03535 & Phosphatidic acid & 0.00271 \\
\hline L-Leucine & 0.03874 & Phosphatidylglycerol & 0.00174 \\
\hline L-Isoleucine & 0.02992 & Tetradecanoic acid & 0.00003 \\
\hline L-Histidine & 0.01067 & Hexadecanoic acid & 0.00073 \\
\hline L-Glutamate & 0.03084 & Palmitoleic acid & 0.00022 \\
\hline L-Cysteine & 0.00410 & Octadecanoic acid & 0.00035 \\
\hline L-Aspartate & 0.02508 & Oleic acid & 0.00163 \\
\hline L-Asparagine & 0.02841 & Linoleate & 0.00054 \\
\hline L-Arginine & 0.02203 & Linolenate & 0.00008 \\
\hline L-Alanine & 0.01334 & Triacylglycerol & 0.00573 \\
\hline Glycine & 0.01077 & Monoacylglycerol & 0.00620 \\
\hline \multirow[t]{2}{*}{ L-Glutamine } & 0.02158 & Diacylglycerol & 0.00087 \\
\hline & & Sterol esters & 0.01177 \\
\hline \multicolumn{2}{|c|}{ Carbohydrates } & & \\
\hline Chitin & 0.01368 & \multicolumn{2}{|c|}{ Soluble Pool } \\
\hline Mannan & 0.14669 & Thiamine & 0.00290 \\
\hline$\beta$ (1.3)-Glucan & 0.23962 & Ubiquinone- 6 & 0.00290 \\
\hline & & $\mathrm{NADP}+$ & 0.00290 \\
\hline \multicolumn{2}{|c|}{ Deoxyribonucleotides } & NAD+ & 0.00290 \\
\hline dTTP & 0.02072 & FMN & 0.00290 \\
\hline dGTP & 0.01266 & FAD & 0.00290 \\
\hline dCTP & 0.01118 & $\mathrm{CoA}$ & 0.00290 \\
\hline dATP & 0.02114 & Biotin & 0.00290 \\
\hline & & Pyridoxal phosphate & 0.00290 \\
\hline \multicolumn{2}{|c|}{ Ribonucleotides } & 5-Methyltetrahydrofolate & 0.00290 \\
\hline UTP & 0.00603 & & \\
\hline GTP & 0.00714 & & \\
\hline CTP & 0.00561 & & \\
\hline ATP & 0.00714 & & \\
\hline
\end{tabular}

Carbohydrate [54], Lipid [55], Sterol [55], Phospholipid [56], and Fatty acid [57] compositions were inferred from literature data. Essential metabolites were included in the biomass composition to qualitatively account for the essentiality of their synthesis pathways $[41,58]$. The growth and non-growth ATP requirements were adopted from S. cerevisiae [59].

\subsection{Validation of the iRV781 Model}

\subsubsection{Carbon and Nitrogen Source Utilization}

Based on the literature, phenotypic growth data were collected from different sources. Data related to $C$. albicans strains, other than the reference SC5314 strain, was also considered in the analysis to increase the number of carbon and nitrogen sources tested.

In a first simulation, this model correctly predicted the usability of $92 \%$ of the 39 tested carbon sources. According to data available on Royal Netherlands Academy of Arts and Sciences 
(CBS-KNAW) Fungal Biodiversity Centre webpage [60], the C. albicans CBS562 strain seems not to be able to use cellobiose or D-ribose as sole carbon sources, contrary to the model's prediction. Therefore, the utilization of cellobiose and D-ribose by C. albicans SC5314 was evaluated experimentally to assess whether the prediction failure could result from a different metabolic capacity exhibited by the reference strain. The results confirmed the model's prediction regarding the utilization of cellobiose and D-Ribose (Figure 3), suggesting that the reference C. albicans strain has higher metabolic capabilities, when compared to other strains. The model's prediction failed only for mannitol that, according to the model, cannot be used as sole carbon source by $C$. albicans, contradicting experimental evidence gathered for the C. albicans SC5314 strain [61,62] (Figure 3). It was not possible to identify the source of this problem in the built model. Nonetheless, the model is able to correctly predict the usability of $97 \%$ of the tested substrates.

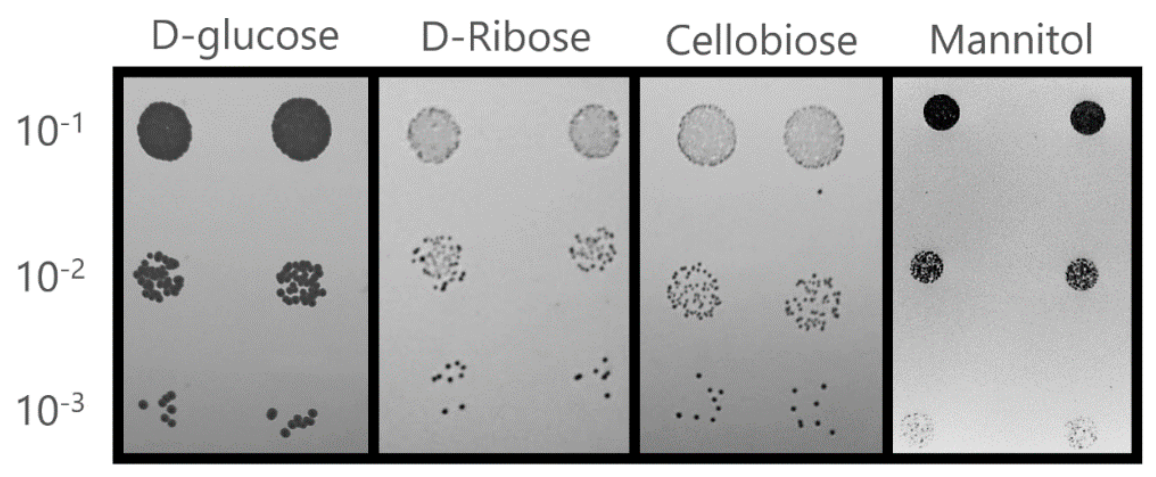

Figure 3. Utilization of glucose (control), cellobiose, D-Ribose, and mannitol by C. albicans reference strain SC5314 as carbon source in solid YNB medium. Initial OD600nm $=0.5 \pm 0.05$. Growth was assessed after incubation at $37^{\circ} \mathrm{C}$ for $24 \mathrm{~h}$.

Altogether, the constructed model proved accurate when predicting the utilization of different carbon and nitrogen sources, when compared to experimental data (Table 3). It correctly predicts the usability of $97 \%$ of the tested carbon sources, and $80 \%$ of the 15 tested nitrogen sources. It should be noted that in the nitrogen tests, none of the literature data was obtained using the reference strain; therefore, it is likely that the C. albicans SC5314 strain is able to use a larger number of nitrogen sources than the previously tested strains. 
Table 3. Comparison between in vivo and in silico phenotypic behavior of $C$. albicans under different carbon and nitrogen sources. Growth (+); lack of growth (-).

\begin{tabular}{|c|c|c|c|}
\hline & \multicolumn{2}{|c|}{ Biomass } & \multirow[b]{2}{*}{ Reference } \\
\hline & In Vivo & In Silico & \\
\hline \multicolumn{4}{|l|}{ Carbon Source } \\
\hline$N$-acetylglucosamine & + & + & {$[62,63]$} \\
\hline Glucose & + & + & [61-63] \\
\hline Maltose & + & + & [63] \\
\hline Galactose & + & + & [61-63] \\
\hline Sucrose & + & + & [63] \\
\hline Fructose & + & + & [61-63] \\
\hline Mannitol & + & - & This study \\
\hline Acetate & + & + & [63] \\
\hline Ethanol & + & + & [63] \\
\hline Glycerol & + & + & [61-63] \\
\hline Mannose & + & + & {$[61,62]$} \\
\hline Citrate & + & + & [60] \\
\hline Lactate & + & + & [62] \\
\hline Sorbitol & + & + & [62] \\
\hline L-sorbose & + & + & [60] \\
\hline D-xylose & + & + & [60] \\
\hline L-rhamnose & - & - & {$[60]$} \\
\hline$\alpha, \alpha$-trehalose & + & + & [60] \\
\hline Cellobiose & + & + & This study \\
\hline Salicin & - & - & [60] \\
\hline Myo-inositol & - & - & [60] \\
\hline D-ribose & + & + & This study \\
\hline Ribitol & - & - & [60] \\
\hline D-glucuronate & - & - & [60] \\
\hline D-galacturonate & - & - & [60] \\
\hline Succinate & + & + & [60] \\
\hline D-gluconate & + & + & [60] \\
\hline Arbutin & - & - & [60] \\
\hline D-arabinose & - & - & {$[60]$} \\
\hline Galactitol & - & - & [60] \\
\hline Starch & + & + & [60] \\
\hline D-glucosamine & + & + & [60] \\
\hline Inulin & - & - & [60] \\
\hline Melibiose & - & - & {$[60]$} \\
\hline Lactose & - & - & [60] \\
\hline Raffinose & - & - & [60] \\
\hline Erythritol & - & - & [60] \\
\hline Xylitol & + & + & [60] \\
\hline L-arabinitol & - & - & [60] \\
\hline \multicolumn{4}{|l|}{ Nitrogen Source } \\
\hline Nitrate & - & - & {$[60,64]$} \\
\hline Nitrite & - & - & {$[60,64]$} \\
\hline Ethylamine & + & - & {$[60]$} \\
\hline L-Lysine & + & + & [60] \\
\hline Ammonia & + & + & {$[60,64]$} \\
\hline Cadaverine & + & - & {$[60]$} \\
\hline Glucosamine & - & + & [60] \\
\hline Creatine & - & - & [60] \\
\hline Creatinine & - & - & [60] \\
\hline Imidazole & - & - & [60] \\
\hline L-asparagine & + & + & {$[60,64]$} \\
\hline Urea & + & + & {$[60,64]$} \\
\hline Hydroxylamine & - & - & {$[60,64]$} \\
\hline Hydrazine & - & - & {$[60,64]$} \\
\hline D-Tryptophan & - & - & [60] \\
\hline
\end{tabular}




\subsubsection{Growth Parameters in Batch Culture}

Experimental data obtained elsewhere [65] from synthetic minimal media batch cultures with glucose as carbon source were used to validate the model quantitatively. The model was simulated in environmental conditions that simulate the medium used in Rozpȩdowska et al., 2011. The glucose uptake flux was fixed to qGlucose $=7.56 \mathrm{mmol} \mathrm{g}^{-1}$ dry weight $\mathrm{h}^{-1}$ as per such work, and the remaining nutrients flux were left unconstrained, as the model in this condition is glucose-limited. Once again, the model proved to be robust as the experimentally observed growth rate is similar to that predicted by the model (Table 4). Additionally, the formation of glycerol, acetic acid, and ethanol as by-products was not predicted to occur, which is in agreement with the experimental data, except for ethanol, that appears to be produced in trace amounts. C. albicans, as a crabtree-negative yeast [66], under aerobic conditions does not produce significant concentrations of ethanol. Nonetheless, the model predicts ethanol production under low-oxygen conditions (qoxygen $<7.56 \mathrm{mmol} \mathrm{g}^{-1}$ dry weight $\mathrm{h}^{-1}$ ).

Table 4. Growth parameters of iRV781 and comparison with in vivo values for C. albicans and S. cerevisiae.

\begin{tabular}{cccccc}
\hline & $\begin{array}{c}\text { Specific Growth } \\
\text { Rate }\left(\mathbf{h}^{\mathbf{- 1}}\right)\end{array}$ & Glucose & Ethanol & Glycerol & Acetic Acid \\
\cline { 3 - 6 } & 0.53 & 7.56 & 0 & 0 & 0 \\
\hline In silico C. albicans & 0.51 & 7.56 & 0.38 & 0 & 0 \\
In vivo C. albicans [60] & 0.38 & 13.26 & 21.87 & 1.98 & $<0.1$ \\
In vivo S. cerevisiae [60] & & dry weight $\left.\mathbf{~ h}^{-\mathbf{1}}\right)$ & \\
\hline
\end{tabular}

C. albicans is unable to grow in anaerobic conditions in minimal media. However, C. albicans colonization is known to spread into anaerobic niches of the gastrointestinal tract or in the inner sections of biofilms where the oxygen availability is scarce or null. Dumitru et al., 2004 reported a defined anaerobic growth medium for studying Candida albicans. In this medium (GPP) oleic acid and nicotinic acid were added as required growth factors for anaerobic growth [67]. Interestingly, S. cerevisiae under anaerobiosis also requires growth factors, such as ergosterol and Tween 80, a source of oleic acid, if growing in a defined medium (SMM), it should be noticed that SMM medium also contains nicotinic acid in its composition despite not being a required growth factor in anaerobic conditions [68]. Cultivation was simulated in the absence of oxygen in GPP medium and GPP medium supplemented with oleic acid and nicotinic acid, to assess if this model can predict growth in anaerobic conditions. Our model predicts the growth only in media supplemented with specific anaerobic growth factors. For the simulation, the glucose uptake flux was set to qGlucose $=6.58 \mathrm{mmol} \mathrm{g}^{-1} \mathrm{dry}_{\text {weight }} \mathrm{h}^{-1}$, to compare the growth parameters with the reported values for $S$. cerevisiae. Indeed, for the same anaerobic conditions, the specific growth rate of the model and the ethanol production are similar to data reported for S. cerevisiae [68], though the model does not predict the production of glycerol in such conditions (Table 5).

Table 5. Anaerobic growth assessment of iRV781 model in defined media with or without anaerobic

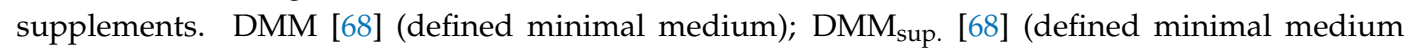

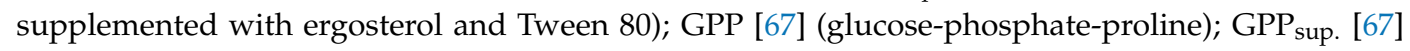
(glucose-phosphate-proline supplemented with oleic acid and nicotinate).

\begin{tabular}{ccccc}
\hline \multirow{2}{*}{ Condition } & $\begin{array}{c}\text { Specific Growth } \\
\left.\text { Rate } \mathbf{h}^{\mathbf{- 1}}\right)\end{array}$ & Glucose & Ethanol & Glycerol \\
\cline { 3 - 5 } & 0 & 0 & 0 & 0 \\
In silico GPP & 0.08 & 6.58 & 10.80 & 0 \\
In silico GPP & 0 & 0 & 0 & 0 \\
In sup. & 0.08 & 6.58 & 10.80 & 0 \\
In silico DMM & 0.10 & 6.58 & 9.47 & 1.11 \\
S. cerevisiae DMM & & & \\
\hline
\end{tabular}




\subsection{Gene Essentiality Assessment: A Tool for Drug Target Discovery?}

A set of C. albicans essential genes [69], were used to evaluate the model's ability to predict essentiality. For each gene a simulation was performed, on the same environmental conditions, described in the reference [69] (YNB medium), eliminating the corresponding reactions for that gene. Only protein-coding genes present in the model were considered. The model was able to correctly predict 78\% (84 out of 108) of the identified essential genes (File S5). It is important to highlight that, in this type of models, the regulatory network is not considered, so it is expected that some predictions are not close to reality.

To evaluate whether the assessment of gene essentiality could be a promising tool in drug target discovery, each one of the identified essential enzymes in the RPMI medium was searched in the DrugBank database [70], as a possible drug target of known antimicrobial agents. RPMI medium simulates human serum, thus allowing to simulate the natural environment faced by Candida albicans in systemic infections.

Interestingly, 11 ERG genes, including the well-known azole drug target ERG11, were predicted by the model to be essential in RPMI medium. Although most ERG genes are not essential, the inhibition of the activity of this pathway has a fungistatic effect indeed. They encode the enzymes that guide the last steps of ergosterol biosynthesis. This pathway is the main target of azole drugs, one of the most common antifungal agents to treat Candida infections [71]. These drugs act by blocking ergosterol biosynthesis inhibiting the Erg11 encoded by the ERG11 gene. When an azole drug binds to this enzyme, ergosterol synthesis is inhibited, leading to lower concentrations of this metabolite in the plasma membrane [72]. Given that ergosterol is part of the C. albicans' biomass, it is acceptable to consider that enzymes that participate in its synthesis pathway can be essential, making most ERG genes attractive alternatives as new drug targets [73].

Many additional proteins stand out as promising new drug targets, including some for which there are already predicted inhibitory drugs, based on the results for homologous proteins in other organisms. For example, Atovaquone is a drug used as a fixed-dose combination with Malarone for treating uncomplicated malaria cases or as chemoprophylaxis in travelers. This drug is an analogue of ubiquinone and targets enzyme 1.3.5.2 encoded by URA9 in Plasmodium falciparum. Atovaquone acts as a competitive inhibitor of ubiquinol inhibiting the mitochondrial electron transport chain at the bc1 complex, resulting in a loss of mitochondrial function [74]. It would be interesting to check if these drugs are also active against $C$. albicans by targeting CaUra9.

Another promising example of a predicted C. albicans drug target is Fol1, which corresponds to enzyme 2.5.1.15. Fol1 is the target of the sulfa drugs (sulfonamides and sulfones), a very well-known class of drugs, used to treat infectious diseases [75]. The effect of sulfa drugs on C. albicans has not been sufficiently investigated. However, it seems that sulfa-fluconazole combination results in increased antifungal activity against $C$. albicans, leading to the reversal of azole resistance in previously resistant strains [76].

Since a reaction can be catalyzed by a protein encoded by more than one gene, and genes may encode more than one protein, we decided to analyze the model's critical reactions. This analysis allowed to increase the number of confirmed drug targets predicted as essential enzymes.

As an example, the FKS genes stand out. They are not considered essential as the enzyme beta-1,3-glucan synthase can be encoded by more than one FKS/GSC/GSL genes [77]. However, the model predicts the reaction in which this enzyme participates as essential. The beta-1,3-glucan synthase is the target of the echinocandin class of antifungal drugs. Via noncompetitive inhibition, these drugs block the enzyme and stop beta-1,3-glucan synthesis, compromising the integrity of the cell wall [78].

Other drugs, such as ethionamide, sulfacetamide, azelaic acid, cerulenin or trimethoprim, were identified as targeting proteins from various organisms. These proteins are homologous to the proteins encoded by genes identified as essential in RPMI, in the C. albicans' model (Table 6). Altogether, these results suggest that the iRV781 model may prove useful in the prediction of new 
drug targets. The predictions of this model may extend to other pathogenic Candida species. In fact, if we search the 12 genes present in Table 6 in emerging non-albicans Candida species, they all have orthologous genes in C. parapsilosis and C. dubliniensis, 11 of them have orthologs in C. auris and 8 of them in C. glabrata.

Despite the methodology for the reconstruction of genome-scale metabolic models being standardized, eukaryotic models remain a challenge, due to their large genomes and complexity [79]. These models always seek to get as close as possible to reality; however, given the complexity of the networks, they are always subject to some errors, which may cause small deviations in the predictions. Some errors may include incorrect assignment of GPR associations, reaction directionality or reversibility, incongruous stoichiometric parameters, missing reactions and inaccurate biomass composition [79]. Additionally, network properties, that go beyond metabolism, cannot be addressed with currently existing modeling tools at a global scale, thus limiting the predictive power that may be drawn from global stoichiometric models. Still, they provide a fresh view of a pathogen's metabolism, while offering a tool to inspect the metabolism itself as a target for new drugs.

Genome-scale metabolic reconstructions are effective in drug target prediction and are expected to continue to expand in the future [80]. Gene essentiality assessment is the most common method to identify potential drug targets, and for a better prediction, it is necessary to consider the medium in which the organism is exposed. In this work, gene essentiality was searched for in RPMI medium in order to simulate the natural environment faced by Candida albicans in systemic infections. However, it is important to highlight that in theses reconstructions, it is not considered that cells may need time to adapt to genetic perturbations or environmental variability [79]. Additionally, yeast interactions with other microorganisms and the secretion of compounds that can influence their surrounding environment are not taken into account [81]. Despite these inaccuracies, genome-scale metabolic reconstructions have proved to be very efficient discovering new drug targets, and once a model is built, drug targets can be predicted relatively easily. In fact, the experimental validation of the targets and the identification of the effective drugs represents a more demanding challenge [82]. 
Table 6. Drug targets evaluated for gene essentiality prediction in RPMI medium, as identified by the iRV781. Data retrieved from DrugBank database; only drugs with known pharmacological action were selected.

\begin{tabular}{|c|c|c|c|c|c|c|c|}
\hline Systematic Name & Standard Name & EC Number & Organism & Drug & PDB Entry & Similarity & Coverage \\
\hline \multirow{2}{*}{ C1_08590C_A } & \multirow{2}{*}{ ERG1 } & \multirow{2}{*}{ 1.14.14.17 } & Candida albicans & Terbinafine & - & - & - \\
\hline & & & Candida albicans & Tolnaftate & - & - & - \\
\hline C1_09720W_A & URA1 & 1.3.5.2 & Plasmodium falciparum & Atovaquone & 5DEL & $37 \%$ & $81 \%$ \\
\hline C2_02460W_A & ERG7 & 5.4.99.7 & Candida albicans & Oxiconazole & - & - & - \\
\hline C5_00190C_A & FAS1 & 1.3.1.9 & $\begin{array}{l}\text { Mycobacterium tuberculosis } \\
\text { Mycobacterium tuberculosis }\end{array}$ & $\begin{array}{l}\text { Ethionamide } \\
\text { Isoniazid }\end{array}$ & $4 \mathrm{~V} 8 \mathrm{~W}$ & $30 \%$ & $45 \%$ \\
\hline C5_00770C_A & FOL1 & 4.1.2.25 & Saccharomyces cerevisiae & Sulfacetamide & $2 \mathrm{BMB}$ & $42 \%$ & $65 \%$ \\
\hline C5_02710W_A & TRR1 & 1.8.1.9 & Staphylococcus aureus & Azelaic acid & 4GCM & $42 \%$ & $98 \%$ \\
\hline C7_03130C_A & DFR1 & 1.5.1.3 & Escherichia coli & Trimethoprim & 4GH8 & $35 \%$ & $77 \%$ \\
\hline \multirow{2}{*}{ C5_00770C_A } & \multirow{2}{*}{ FOL1 } & \multirow{2}{*}{ 2.5.1.15 } & \multirow{2}{*}{$\begin{array}{l}\text { Escherichia coli } \\
\text { P. falciparum }\end{array}$} & Sulfonamides and sulfones & 1AJ2 & $36 \%$ & $40 \%$ \\
\hline & & & & Sulfonamides and sulfones & $6 \mathrm{KCM}$ & $26 \%$ & $65 \%$ \\
\hline C1_02420C_A & GSC1 & \multirow{3}{*}{ 2.4.1.34 } & Candida albicans & Anidulafungin & - & - & - \\
\hline C1_05600W_A & GSL1 & & Candida albicans & Caspofungin & - & - & - \\
\hline CR_00850C_A & GSL2 & & Candida albicans & Micafungin & - & - & - \\
\hline C3_04830C_A & FAS2 & 2.3.1.41 & Escherichia coli & Cerulenin & $2 B Y X$ & $31 \%$ & $8 \%$ \\
\hline CR_00850C_A & ERG11 & 1.14.14.154 & Candida albicans & Azoles & - & - & - \\
\hline
\end{tabular}




\section{Conclusions}

The first validated global metabolic model for the human pathogen C. albicans is presented in this study. The model was manually curated and validated thoroughly, constituting a powerful platform for the study of $C$. albicans metabolic potential and weaknesses. The iRV781 model includes 781 genes associated with 1221 reactions, the number of reactions in the main pathways being similar to those in C. glabrata and S. cerevisiae models. However, about $20 \%$ of the proteins associated with EC numbers in iRV781 are unique in relation to these models. The model proved accurate when predicting the utilization of different carbon and nitrogen sources, and in anaerobic growth in defined anaerobic media. In silico growth parameters are also in agreement with the experimental data. We were able to identifyas essential genes in RPMI medium some which are already known targets antifungal agents and other antimicrobial agents used in clinical practice. This observation suggests that the C. albicans global stoichiometric model, presented herein, may be a promising platform for the identification of further targets for new antifungal drugs.

Supplementary Materials: The following are available online at http://www.mdpi.com/2309-608X/6/3/171/s1, Figure S1: C. albicans phylogenetic tree, File S1: Biomass equation, File S2: Model curation, File S3: Unique EC number, File S4: iRV781 sbml file, File S5: Gene essentiality.

Author Contributions: R.V., O.D. and D.L. constructed and validated the presented model. R.V. and M.G. conducted the wet-lab experiments. R.V., O.D., I.R. and M.C.T. wrote the paper. M.C.T. and I.R. raised funding and conceived and supervised all the work. All authors have read and agreed to the published version of the manuscript.

Funding: This research was funded by "Fundação para a Ciência e a Tecnologia" (FCT) [Contract PTDC /BII-BIO/28216/2017] and by Programa Operacional Regional de Lisboa 2020 [LISBOA-01-0145-FEDER-022231], through the Biodata.pt Research Infrastructure. Funding received by iBB-Institute for Bioengineering and Biosciences from FCT [Contract UIDB/04565/2020] is also acknowledged.

Acknowledgments: Technical support given by José Bastos and Sophia Santos, CEB, UMinho, is acknowledged.

Conflicts of Interest: The authors declare no conflict of interest. The funders had no role in the design of the study; in the collection, analyses, or interpretation of data; in the writing of the manuscript, or in the decision to publish the results.

\section{References}

1. Wisplinghoff, H.; Bischoff, T.; Tallent, S.M.; Seifert, H.; Wenzel, R.; Edmond, M.B. Nosocomial bloodstream infections in US hospitals: Analysis of 24,179 cases from a prospective nationwide surveillance study. Clin. Infect. Dis. 2004, 39, 309-317. [CrossRef]

2. Perlroth, J.; Choi, B.; Spellberg, B. Nosocomial fungal infections: Epidemiology, diagnosis, and treatment. Med. Mycol. 2007, 45, 321-346. [CrossRef]

3. Yapar, N. Epidemiology and risk factors for invasive candidiasis. Ther. Clin. Risk Manag. 2014, 10, 95-105. [CrossRef]

4. Horn, D.L.; Neofytos, D.; Anaissie, E.J.; Fishman, J.A.; Steinbach, W.J.; Olyaei, A.J.; Marr, K.A.; Pfaller, M.A.; Chang, C.-H.; Webster, K.M. Epidemiology and outcomes of candidemia in 2019 patients: Data from the prospective antifungal therapy alliance registry. Clin. Infect. Dis. 2009, 48, 1695-1703. [CrossRef]

5. Galocha, M.; Pais, P.; Cavalheiro, M.; Pereira, D.; Viana, R.; Teixeira, M. Divergent approaches to virulence in C. albicans and C. glabrata: Two sides of the same coin. Int. J. Mol. Sci. 2019, 20, 2345. [CrossRef]

6. Cavalheiro, M.; Teixeira, M. Candida biofilms: Threats, challenges, and promising strategies. Front. Med. 2018, 5. [CrossRef]

7. Hampe, I.A.I.; Friedman, J.; Edgerton, M.; Morschhäuser, J. An acquired mechanism of antifungal drug resistance simultaneously enables Candida albicans to escape from intrinsic host defenses. PLoS Pathog. 2017, 13, e1006655. [CrossRef] 
8. Pfaller, M.A.; Rhomberg, P.; Messer, S.; Jones, R.; Castanheira, M. Isavuconazole, micafungin, and 8 comparator antifungal agents' susceptibility profiles for common and uncommon opportunistic fungi collected in 2013: Temporal analysis of antifungal drug resistance using CLSI species-specific clinical breakpoints and proposed epidemiological cutoff values. Diagn. Microbiol. Infect. Dis. 2015, 82, 303-313. [CrossRef]

9. Cleveland, A.A.; Farley, M.M.; Harrison, L.H.; Stein, B.; Hollick, R.; Lockhart, S.R.; Magill, S.S.; Derado, G.; Park, B.J.; Chiller, T.M. Changes in incidence and antifungal drug resistance in candidemia: Results from population-based laboratory surveillance in atlanta and baltimore, 2008-2011. Clin. Infect. Dis. 2012, 55, 1352-1361. [CrossRef]

10. Arendrup, M.C.; Patterson, T.F. Multidrug-resistant Candida: Epidemiology, molecular mechanisms, and treatment. J. Infect. Dis. 2017, 216, S445-S451. [CrossRef]

11. Pham, C.D.; Iqbal, N.; Bolden, C.B.; Kuykendall, R.J.; Harrison, L.H.; Farley, M.M.; Schaffner, W.; Beldavs, Z.G.; Chiller, T.M.; Park, B.J.; et al. Role of FKS mutations in Candida glabrata: MIC values, echinocandin resistance, and multidrug resistance. Antimicrob. Agents Chemother. 2014, 58, 4690-4696. [CrossRef]

12. Pfaller, M.; Messer, S.A.; Woosley, L.N.; Jones, R.N.; Castanheira, M. Echinocandin and triazole antifungal susceptibility profiles for clinical opportunistic yeast and mold isolates collected from 2010 to 2011: Application of new CLSI clinical breakpoints and epidemiological cutoff values for characterization of geographic and temporal trends of antifungal resistance. J. Clin. Microbiol. 2013, 51, 2571-2581. [CrossRef]

13. Lockhart, S.R.; Etienne, K.A.; Vallabhaneni, S.; Farooqi, J.; Chowdhary, A.; Govender, N.P.; Colombo, A.L.; Calvo, B.; Cuomo, C.A.; Desjardins, C.A.; et al. Simultaneous emergence of multidrug-resistant Candida auris on 3 continents confirmed by whole-genome sequencing and epidemiological analyses. Clin. Infect. Dis. 2016, 64, 134-140. [CrossRef]

14. Dias, O.; Pereira, R.; Gombert, A.K.; Ferreira, E.C.; Rocha, I. iOD907, the first genome-scale metabolic model for the milk yeast Kluyveromyces lactis. Biotechnol. J. 2014, 9, 776-790. [CrossRef]

15. Kim, T.Y.; Kim, H.U.; Lee, S.Y. Metabolite-centric approaches for the discovery of antibacterials using genome-scale metabolic networks. Metab. Eng. 2010, 12, 105-111. [CrossRef]

16. Raškevičius, V.; Mikalayeva, V.; Antanavičiūtè, I.; Ceslevičienė, I.; Skeberdis, V.A.; Kairys, V.; Bordel, S. Genome scale metabolic models as tools for drug design and personalized medicine. PLoS ONE 2018, 13, e0190636. [CrossRef]

17. Robinson, J.; Nielsen, J. Anticancer drug discovery through genome-scale metabolic modeling. Curr. Opin. Syst. Biol. 2017, 4, 1-8. [CrossRef]

18. Mienda, B.S.; Salihu, R.; Adamu, A.; Idris, S. Genome-scale metabolic models as platforms for identification of novel genes as antimicrobial drug targets. Futur. Microbiol. 2018, 13, 455-467. [CrossRef]

19. Dias, O.; Saraiva, J.; Faria, C.; Ramirez, M.; Pinto, F.R.; Rocha, I. iDS372, a phenotypically reconciled model for the metabolism of streptococcus pneumoniae strain R6. Front. Microbiol. 2019, 10, 10. [CrossRef]

20. Abdel-Haleem, A.M.; Hefzi, H.; Mineta, K.; Gao, X.; Gojobori, T.; Palsson, B.O.; Lewis, N.E.; Jamshidi, N. Functional interrogation of Plasmodium genus metabolism identifies species and stage-specific differences in nutrient essentiality and drug targeting. PLoS Comput. Biol. 2018, 14, e1005895. [CrossRef]

21. Rocha, I.; Maia, P.; Evangelista, P.; Vilaça, P.; Soares, S.; Pinto, J.P.B.G.P.; Nielsen, J.; Patil, K.R.; Ferreira, E.C.; Rocha, M. OptFlux: An open-source software platform for in silico metabolic engineering. BMC Syst. Biol. 2010, 4, 45. [CrossRef]

22. Heirendt, L.; Arreckx, S.; Pfau, T.; Mendoza, S.N.; Richelle, A.; Heinken, A.; Haraldsdóttir, H.S.; Wachowiak, J.; Keating, S.M.; Vlasov, V.; et al. Creation and analysis of biochemical constraint-based models using the COBRA Toolbox v.3. Nat. Protoc. 2019, 14, 639-702. [CrossRef]

23. Dias, O.; Rocha, M.; Ferreira, E.C.; Rocha, I. Reconstructing genome-scale metabolic models with merlin. Nucleic Acids Res. 2015, 43, 3899-3910. [CrossRef]

24. Dias, O.; Rocha, M.; Ferreira, E.C.; Rocha, I. Reconstructing high-quality large-scale metabolic models with merlin. Adv. Struct. Saf. Stud. 2017, 1716, 1-36. [CrossRef]

25. Kitts, P.A.; Church, D.M.; Thibaud-Nissen, F.; Choi, J.; Hem, V.; Sapojnikov, V.; Smith, R.G.; Tatusova, T.; Xiang, C.; Zherikov, A.; et al. Assembly: A resource for assembled genomes at NCBI. Nucleic Acids Res. 2015, 44, D73-D80. [CrossRef]

26. Federhen, S. The NCBI taxonomy database. Nucleic Acids Res. 2011, 40, D136-D143. [CrossRef] 
27. Kumar, S.; Stecher, G.; Li, M.; Knyaz, C.; Tamura, K. MEGA X: Molecular evolutionary genetics analysis across computing platforms. Mol. Biol. Evol. 2018, 35, 1547-1549. [CrossRef]

28. Tamura, K.; Nei, M. Estimation of the number of nucleotide substitutions in the control region of mitochondrial DNA in humans and chimpanzees. Mol. Biol. Evol. 1993, 10. [CrossRef]

29. Altschul, S.F.; Gish, W.; Miller, W.; Myers, E.W.; Lipman, D.J. Basic local alignment search tool. J. Mol. Biol. 1990, 215, 403-410. [CrossRef]

30. Boutet, E.; Lieberherr, D.; Tognolli, M.; Schneider, M.; Bansal, P.; Bridge, A.; Poux, S.; Bougueleret, L.; Xenarios, I. UniProtKB/Swiss-prot, the manually annotated section of the UniProt knowledgebase: How to use the entry view. Adv. Struct. Saf. Stud. 2016, 1374, 23-54. [CrossRef]

31. Finn, R.D.; Clements, J.; Eddy, S.R. HMMER web server: Interactive sequence similarity searching. Nucleic Acids Res. 2011, 39 (Suppl. S2), W29-W37. [CrossRef] [PubMed]

32. Placzek, S.; Schomburg, I.; Chang, A.; Jeske, L.; Ulbrich, M.; Tillack, J.; Schomburg, D. BRENDA in 2017: New perspectives and new tools in BRENDA. Nucleic Acids Res. 2016, 45, D380-D388. [CrossRef] [PubMed]

33. Stelzer, M.; Sun, J.; Kamphans, T.; Fekete, S.P.; Zeng, A.-P. An extended bioreaction database that significantly improves reconstruction and analysis of genome-scale metabolic networks. Integr. Biol. 2011, 3, 1071-1086. [CrossRef] [PubMed]

34. Schomburg, D. BRENDA, enzyme data and metabolic information. Nucleic Acids Res. 2002, 30, 47-49. [CrossRef] [PubMed]

35. Caspi, R.; Altman, T.; Billington, R.; Dreher, K.; Foerster, H.; Fulcher, C.A.; Holland, T.A.; Keseler, I.M.; Kothari, A.; Kubo, A.; et al. The MetaCyc database of metabolic pathways and enzymes and the BioCyc collection of Pathway/Genome Databases. Nucleic Acids Res. 2013, 42, D471-D480. [CrossRef]

36. Ogata, H.; Goto, S.; Sato, K.; Fujibuchi, W.; Bono, H.; Kanehisa, M. KEGG: Kyoto encyclopedia of genes and genomes. Nucleic Acids Res. 1999, 27, 29-34. [CrossRef]

37. Horton, P.; Park, K.-J.; Obayashi, T.; Fujita, N.; Harada, H.; Adams-Collier, C.; Nakai, K. WoLF PSORT: Protein localization predictor. Nucleic Acids Res. 2007, 35, W585-W587. [CrossRef]

38. Santos, S.; Rocha, I. Estimation of biomass composition from genomic and transcriptomic information. J. Integr. Bioinform. 2016, 13, 1-14. [CrossRef]

39. Verduyn, C. Physiology of yeasts in relation to biomass yields. Antonie van Leeuwenhoek 1991, 60, 325-353. [CrossRef]

40. Mishra, P.; Park, G.; Lakshmanan, M.; Lee, H.; Lee, H.; Chang, M.W.; Ching, C.B.; Ahn, J.O.; Lee, N.-Y. Genome-scale metabolic modeling and in silico analysis of lipid accumulating yeastCandida tropicalisfor dicarboxylic acid production. Biotechnol. Bioeng. 2016, 113, 1993-2004. [CrossRef]

41. Xu, N.; Liu, L.; Zou, W.; Liu, J.; Hua, Q.; Chen, J. Reconstruction and analysis of the genome-scale metabolic network of Candida glabrata. Mol. BioSyst. 2013, 9, 205-216. [CrossRef] [PubMed]

42. Mo, M.L.; Palsson, B.O.; Herrgård, M.J. Connecting extracellular metabolomic measurements to intracellular flux states in yeast. BMC Syst. Biol. 2009, 3, 37. [CrossRef] [PubMed]

43. Oliveros, J.C. VENNY. An interactive tool for comparing lists with Venn Diagrams. Int. J. Proteom. 2014. Available online: http://bioinfogp.cnb.csic.es/tools/venny/index.html (accessed on 11 September 2007).

44. Xu, D.; Jiang, B.; Ketela, T.; Lemieux, S.; Veillette, K.; Martel, N.; Davison, J.; Sillaots, S.; Trosok, S.; Bachewich, C.; et al. Genome-wide fitness test and mechanism-of-action studies of inhibitory compounds in Candida albicans. PLoS Pathog. 2007, 3, e92. [CrossRef]

45. Greenberg, J.R.; Price, N.P.; Oliver, R.P.; Sherman, F.; Rustchenko, E. Candida albicans SOU1 encodes a sorbose reductase required forL-sorbose utilization. Yeast 2005, 22, 957-969. [CrossRef] [PubMed]

46. Gao, J.; Wang, H.; Li, Z.; Wong, A.H.-H.; Wang, Y.-Z.; Guo, Y.; Lin, X.; Zeng, G.; Liu, H.; Wang, Y.; et al. Candida albicans gains azole resistance by altering sphingolipid composition. Nat. Commun. 2018, 9, 4495. [CrossRef]

47. Hüdig, M.; Maier, A.; Scherrers, I.; Seidel, L.; Jansen, E.E.; Mettler-Altmann, T.; Engqvist, M.K.M.; Maurino, V.G. Plants possess a cyclic mitochondrial metabolic pathway similar to the mammalian metabolic repair mechanism involving malate dehydrogenase and 1-2-hydroxyglutarate dehydrogenase. Plant Cell Physiol. 2015, 56, 1820-1830. [CrossRef] 
48. Rzem, R.; Veiga-Da-Cunha, M.; Noël, G.; Goffette, S.; Nassogne, M.-C.; Tabarki, B.; Schöller, C.; Marquardt, T.; Vikkula, M.; Van Schaftingen, E. A gene encoding a putative FAD-dependent L-2-hydroxyglutarate dehydrogenase is mutated in L-2-hydroxyglutaric aciduria. Proc. Natl. Acad. Sci. USA 2004, 101, 16849-16854. [CrossRef]

49. Wendland, J.; Schaub, Y.; Walther, A. N-acetylglucosamine utilization by saccharomyces cerevisiae based on expression of Candida albicans NAG genes. Appl. Environ. Microbiol. 2009, 75, 5840-5845. [CrossRef]

50. Vesely, E.M.; Williams, R.B.; Konopka, J.B.; Lorenz, M.C. N-acetylglucosamine metabolism promotes survival of Candida albicans in the phagosome. mSphere 2017, 2, e00357-17. [CrossRef]

51. Molla, G.; Motteran, L.; Piubelli, L.; Pilone, M.S.; Pollegioni, L. Regulation ofD-amino acid oxidase expression in the yeastRhodotorula gracilis. Yeast 2003, 20, 1061-1069. [CrossRef] [PubMed]

52. Thiele, I.; Palsson, B.O. A protocol for generating a high-quality genome-scale metabolic reconstruction. Nat. Protoc. 2010, 5, 93-121. [CrossRef] [PubMed]

53. Santos, S.T. Development of Computational Methods for the Determination of Biomass Composition and Evaluation of Its Impact in Genome-Scale Models Predictions. Master's Thesis, Universidade do Minho, Braga, Portugal, 2013.

54. Brondz, I.; Olsen, I. Multivariate analyses of cellular carbohydrates and fatty acids of Candida albicans, torulopsis glabrata, and saccharomyces cerevisiae. J. Clin. Microbiol. 1990, 28, 1854-1857. [CrossRef]

55. Ghannoum, M.; Swairjo, I.; Soll, D. Variation in lipid and sterol contents inCandida albicanswhite and opaque phenotypes. Med. Mycol. 1990, 28, 103-115. [CrossRef]

56. Abu-Elteen, K.H.; Whittaker, P.A. Effect of sub-inhibitory concentration of chlorhexidine on lipid and sterol composition of shape Candida albicans. Mycopathol 1997, 140, 69-76. [CrossRef] [PubMed]

57. Mayatepek, E.; Herz, A.; Leichsenring, M.; Kappe, R. Fatty acid analysis of different Candida, species by capillary column gas-liquid chromatography. Mycoses 2009, 34, 53-57. [CrossRef]

58. Xavier, J.C.; Patil, K.R.; Rocha, I. Integration of biomass formulations of genome-scale metabolic models with experimental data reveals universally essential cofactors in prokaryotes. Metab. Eng. 2017, 39, 200-208. [CrossRef] [PubMed]

59. Verduyn, C.; Postma, E.; Scheffers, W.A.; Van Dijken, J.P. Physiology of saccharomyces cerevisiae in anaerobic glucose-limited chemostat culturesx. J. Gen. Microbiol. 1990, 136, 395-403. [CrossRef]

60. CBS-KNAW Collections. Available online: http://www.cbs.knaw.nl/Collections (accessed on 24 July 2020).

61. Brown, V.; Sexton, J.A.; Johnston, M. A Glucose Sensor in Candida albicans. Eukaryot. Cell 2006, 5, $1726-1737$. [CrossRef]

62. Huang, X.; Chen, X.; He, Y.; Yu, X.; Li, S.; Gao, N.; Niu, L.; Mao, Y.; Wang, Y.; Wu, X.; et al. Mitochondrial complex I bridges a connection between regulation of carbon flexibility and gastrointestinal commensalism in the human fungal pathogen Candida albicans. PLoS Pathog. 2017, 13, e1006414. [CrossRef]

63. Guan, G.; Wang, H.; Liang, W.; Cao, C.; Tao, L.; Naseem, S.; Konopka, J.; Wang, Y.; Huang, G. The mitochondrial protein Mcu1 plays important roles in carbon source utilization, filamentation, and virulence in Candida albicans. Fungal Genet. Biol. 2015, 81, 150-159. [CrossRef] [PubMed]

64. Choudary, P.V.; Rao, G.R. Molecular analysis of inorganic nitrogen assimilation in yeasts. Arch. Microbiol. 1984, 138, 183-186. [CrossRef]

65. Rozpędowska, E.; Galafassi, S.; Johansson, L.; Hagman, A.; Piškur, J.; Compagno, C. Candida albicans a pre-whole genome duplication yeast-Is predominantly aerobic and a poor ethanol producer. FEMS Yeast Res. 2011, 11, 285-291. [CrossRef] [PubMed]

66. Askew, C.; Sellam, A.; Epp, E.; Hogues, H.; Mullick, A.; Nantel, A.; Whiteway, M. Transcriptional regulation of carbohydrate metabolism in the human pathogen Candida albicans. PLoS Pathog. 2009, 5, e1000612. [CrossRef]

67. Dumitru, R.; Hornby, J.M.; Nickerson, K.W. Defined anaerobic growth medium for studying Candida albicans basic biology and resistance to eight antifungal drugs. Antimicrob. Agents Chemother. 2004, 48, 2350-2354. [CrossRef]

68. Jouhten, P.; Rintala, E.; Huuskonen, A.; Tamminen, A.; Toivari, M.; Wiebe, M.G.; Ruohonen, L.; Penttilä, M.; Maaheimo, H. Oxygen dependence of metabolic fluxes and energy generation of Saccharomyces cerevisiae CEN.PK113-1A. BMC Syst. Biol. 2008, 2, 60. [CrossRef]

69. O’Meara, T.; Veri, A.O.; Ketela, T.; Jiang, B.; Roemer, T.; Cowen, L.E. Global analysis of fungal morphology exposes mechanisms of host cell escape. Nat. Commun. 2015, 6, 6741. [CrossRef] 
70. Wishart, D.S. DrugBank: A comprehensive resource for in silico drug discovery and exploration. Nucleic Acids Res. 2006, 34, D668-D672. [CrossRef]

71. Robbins, N.; Wright, G.D.; Cowen, L.E. Antifungal drugs: The current armamentarium and development of new agents. Fungal Kingd. 2017, 4, 903-922. [CrossRef]

72. Lupetti, A. Molecular basis of resistance to azole antifungals. Trends Mol. Med. 2002, 8, 76-81. [CrossRef]

73. Rodrigues, M.L. The multifunctional fungal ergosterol. mBio 2018, 9, e01755-18. [CrossRef] [PubMed]

74. Nixon, G.L.; Moss, D.M.; Shone, A.E.; Lalloo, D.G.; Fisher, N.; O’Neill, P.M.; Ward, S.; Biagini, G.A. Antimalarial pharmacology and therapeutics of atovaquone. J. Antimicrob. Chemother. 2013, 68, 977-985. [CrossRef] [PubMed]

75. Iliades, P.; Berglez, J.; Meshnick, S.; Macreadie, I. Promoter strength of folic acid synthesis genes affects sulfa drug resistance in saccharomyces cerevisiae. Microb. Drug Resist. 2003, 9, 249-255. [CrossRef] [PubMed]

76. Eldesouky, H.E.; Mayhoub, A.; Hazbun, T.R.; Seleem, M.N. Reversal of azole resistance in Candida albicansby sulfa antibacterial drugs. Antimicrob. Agents Chemother. 2017, 62, e00701-17. [CrossRef]

77. Garcia-Effron, G.; Lee, S.; Park, S.; Cleary, J.D.; Perlin, D.S. Effect of Candida glabrata FKS1 and FKS2 mutations on echinocandin sensitivity and kinetics of 1,3- $\beta$-d-glucan synthase: Implication for the existing susceptibility breakpoint. Antimicrob. Agents Chemother. 2009, 53, 3690-3699. [CrossRef]

78. Walker, L.A.; Gow, N.A.R.; Munro, C.A. Fungal echinocandin resistance. Fungal Genet. Biol. 2010, 47, 117-126. [CrossRef]

79. Lopes, H.; Rocha, I. Genome-scale modeling of yeast: Chronology, applications and critical perspectives. FEMS Yeast Res. 2017, 17, 50. [CrossRef]

80. Chavali, A.K.; D’Auria, K.M.; Hewlett, E.L.; Pearson, R.D.; Papin, J.A. A metabolic network approach for the identification and prioritization of antimicrobial drug targets. Trends Microbiol. 2012, 20, 113-123. [CrossRef]

81. Jouhten, P.; Ponomarova, O.; Gonzalez, R.; Patil, K.R. Saccharomyces cerevisiae metabolism in ecological context. FEMS Yeast Res. 2016, 16, 80. [CrossRef]

82. Gu, C.; Kim, G.B.; Kim, W.J.; Kim, H.U.; Lee, S.Y. Current status and applications of genome-scale metabolic models. Genome Biol. 2019, 20, 121. [CrossRef] 